\title{
A comprehensive protocol for ventilator weaning and extubation: a prospective observational study
}

Kenichi Nitta* ${ }^{*}$, Kazufumi Okamoto, Hiroshi Imamura, Katsunori Mochizuki, Hiroshi Takayama, Hiroshi Kamijo, Mayumi Okada, Kanako Takeshige, Yuichiro Kashima and Takahisa Satou

\begin{abstract}
Background: Ventilator weaning protocols have been shown to reduce the duration of mechanical ventilation (MV), intensive care unit length of stay, and resource use. However, weaning protocols have not significantly affected mortality or reintubation rates. The extubation process is a critical component of respiratory care in patients who receive MV. Post-extubation respiratory failure (PERF) is a common event associated with significant morbidity and mortality. We hypothesized that a comprehensive protocol for ventilator weaning and extubation would be effective for preventing PERF and reintubation and reducing mortality in critically ill patients.
\end{abstract}

Methods: A ventilator weaning and extubation protocol was developed. The protocol consisted of checklists across four evaluations: spontaneous breathing trial, extubation, prophylactic non-invasive positive pressure ventilation (NPPV), and evaluation after extubation. Observational data were collected after implementing the protocol in patients admitted to the Advanced Emergency and Critical Care Center of Shinshu University Hospital. Not only outcomes of patients but also influences of each component of the protocol on the clinical decision-making process were investigated. Further, a comparison between PERF and non-PERF patients was performed.

Results: A total of 464 consecutive patients received MV for more than $48 \mathrm{~h}$, and 248 (77 women; mean age, $65 \pm$ 17 years) were deemed eligible. The overall PERF and reintubation rates were $9.7 \%$ and $5.2 \%$, respectively. Overall, $54.1 \%$ of patients with PERF received reintubation. Hospital stay and mortality were not significantly different between PERF and non-PERF patients ( $p=0.16$ and 0.057 , respectively). As a result, the 28-day and hospital mortality were $1.2 \%$ and $6.9 \%$, respectively.

Conclusions: We found that the rates of PERF, reintubation, and hospital mortality were lower than those in previous reports even with nearly the same degree of severity at extubation. The comprehensive protocol for ventilator weaning and extubation may prevent PERF and reintubation and reduce mortality in critically ill patients.

Keywords: Comprehensive protocol for ventilator weaning and extubation, Hospital mortality, Post-extubation respiratory failure, Reintubation

\footnotetext{
* Correspondence: nittaken@shinshu-u.ac.jp

Department of Emergency and Critical Care Medicine, Shinshu University

School of Medicine, 3-1-1 Asahi, Matsumoto, Nagano 390-8621, Japan
}

(c) The Author(s). 2019 Open Access This article is distributed under the terms of the Creative Commons Attribution 4.0 International License (http://creativecommons.org/licenses/by/4.0/), which permits unrestricted use, distribution, and

reproduction in any medium, provided you give appropriate credit to the original author(s) and the source, provide a link to the Creative Commons license, and indicate if changes were made. The Creative Commons Public Domain Dedication waiver (http://creativecommons.org/publicdomain/zero/1.0/) applies to the data made available in this article, unless otherwise stated. 


\section{Background}

Weaning protocols have become popularized since the publication of guidelines by the task force on ventilator discontinuation in 2001 [1]. Several studies have reported that weaning protocols reduced the total duration of ventilation, weaning duration, and intensive care unit (ICU) length of stay without impacting mortality or adverse events [2-4].

Meanwhile, the extubation process is a critical component of respiratory care in patients who receive mechanical ventilation (MV). Post-extubation respiratory failure (PERF) is a common event associated with significant morbidity and mortality [5]. It can be caused by upper airway obstruction or the inability to protect the airway and clear secretions in addition to causes of ventilatorwithdrawal failure [6]. Thus, the decision to extubate requires further assessment of the patient's ability to avert PERF. Many studies that have assessed the need for artificial airway have been reported [4, 7-9]. However, there is no definite guideline for the extubation process.

Insufficient evidence is available regarding a systematic approach for ventilator weaning and extubation. Therefore, we developed a comprehensive protocol for ventilator weaning and extubation based on the screening of meaningful physiologic and clinical variables followed by a spontaneous breathing trial (SBT). Furthermore, prophylactic use of non-invasive positive pressure ventilation (NPPV) was included in our protocol. We hypothesized that the comprehensive protocol would be effective for preventing PERF and reintubation and reducing mortality of critically ill patients.

\section{Methods}

This prospective observational cohort study included all patients who received MV under tracheal intubation in the Advanced Emergency and Critical Care Center of Shinshu University Hospital. This study was approved by the Ethics Review Board of Shinshu University School of Medicine (Approval Number: 2652). The requirement for informed patient consent was waived since the protocol was deemed critical for improving patient care.

\section{Patient selection}

All patients who required MV under tracheal intubation for $48 \mathrm{~h}$ or more between April 2007 and March 2013 at the study center were eligible. During this period, for all consecutive adults, we prospectively implemented a comprehensive protocol for ventilator weaning and extubation. Patients were excluded from the study if they were below 18 years of age, died under MV, received tracheostomy, had self-extubation before or after fulfilling the conditions for SBT, were transferred to our center under MV, or were under a do-not-resuscitate status.

\section{Comprehensive protocol for ventilator weaning and extubation}

We developed a protocol for ventilator weaning and extubation $[1,10,11]$. This protocol consists of four risk assessment checklists: (1) tolerance of SBT, (2) eligibility for extubation, (3) evaluation for the use of prophylactic NPPV, and (4) evaluation after extubation (Figs. 1 and 2 ). If the first risk assessment checklist was passed, both second and third checklists were assessed simultaneously. Patients were extubated if they met all seven criteria of the eligibility for extubation (second risk assessment checklist); if not, MV was continued, and items in this checklist were rechecked the next day. If a patient has at least one of the three criteria in the third risk assessment checklist, the use of prophylactic NPPV is considered. The final decision on the use of prophylactic NPPV is left to the discretion of the attending physicians. The evaluation after extubation (fourth risk assessment checklist) involved evaluation within $48 \mathrm{~h}$ after extubation. Attending physicians checked this checklist $60 \mathrm{~min}$ after extubation, every morning and evening. Furthermore, if the ICU nurses noticed at least one abnormality out of six criteria during the once every hour physical assessment, they told the attending physicians about the abnormality. Then, the attending physician rechecked the checklist in each case. Patients who met at least one of the six criteria of this risk assessment checklist were adjudged as PERF and were administered rescue NPPV or reintubation. Rescue NPPV was applied following the protocol proposed by Kikuchi et al. [12]. The protocol for NPPV comprised of six checklists: (1) the need for ventilatory assistance, (2) the eligibility for NPPV, (3) the effectiveness evaluation at 30-120 min after the start of NPPV, (4) the effectiveness evaluation at $12-24 \mathrm{~h}$ after the start of NPPV, (5) the eligibility for weaning, and (6) the evaluation at 30-120 min after the discontinuation of NPPV [12]. We used the first four of the checklists in Kikuchi et al.'s protocol, leaving out the fifth and sixth checklists. For patients who did not fulfill each checklist, reintubation was performed. Patients who did not meet any of the six evaluation criteria for the fourth risk assessment checklist were continued on conventional oxygen therapy. The protocol was executed mainly by residents under the tutoring of intensivists.

\section{Data collection and outcome variables}

In all patients, the following parameters were recorded before extubation: heart rate, mean arterial pressure, respiratory rate, Glasgow Coma Scale score under tracheal intubation $\left(\mathrm{GCS}_{T}\right.$ score), arterial blood gas (ABG) analysis, Acute Physiology and Chronic Health Evaluation (APACHE) II score, sequential organ failure assessment score under tracheal intubation $\left(\mathrm{SOFA}_{T}\right.$ score), and rapid shallow breathing index (RSBI). Outcome variables 


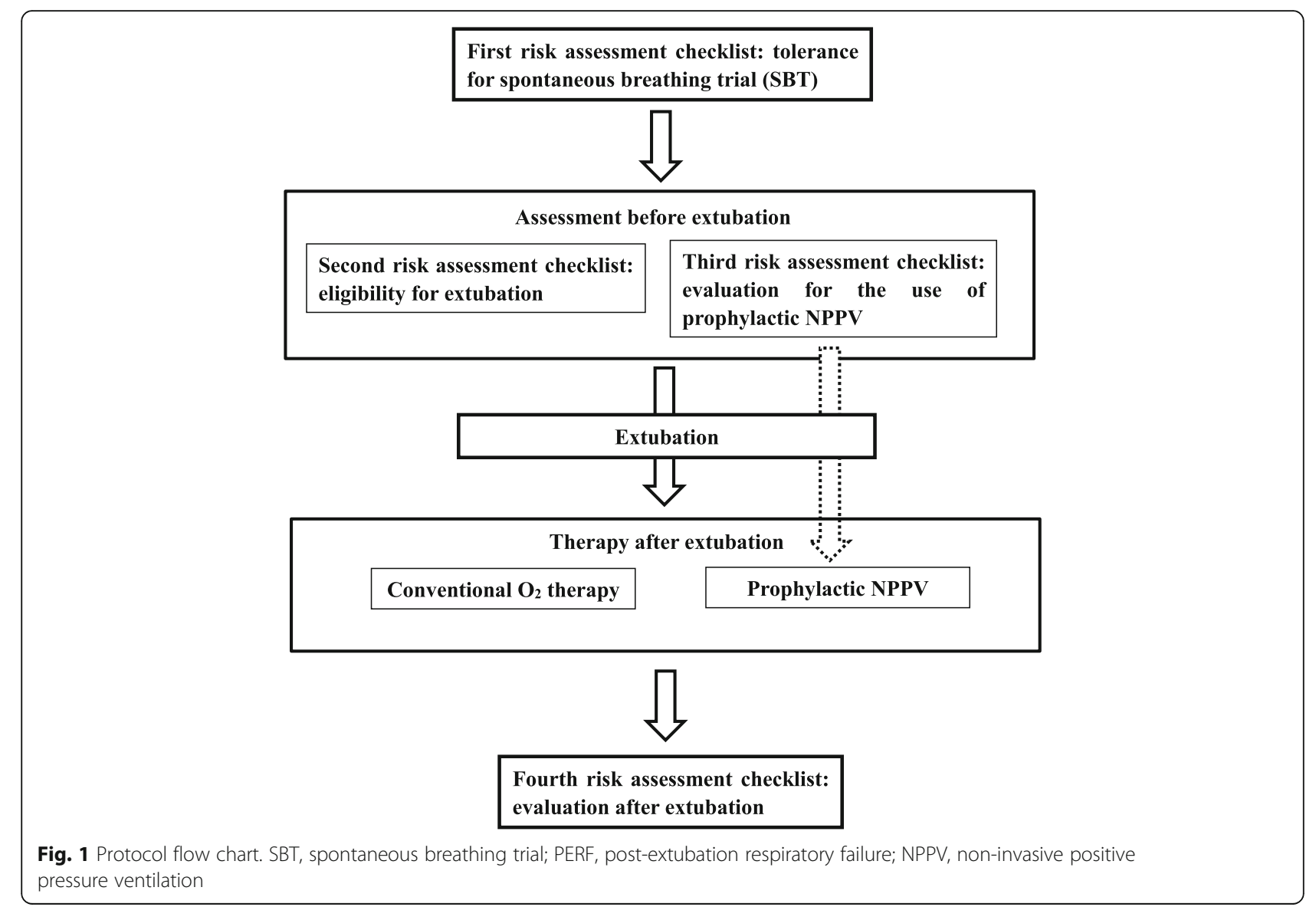

included PERF and reintubation rates, lengths of critical care center (CCC) and hospital stay, and 28-day, 60-day, and hospital mortality. While RSBI was defined as the ratio of respiratory rate to tidal volume, $\mathrm{GCS}_{T}$, and SOFA $_{T}$ scores were defined based on the description by Coplin et al. [13]; the verbal component of the GCS was arbitrarily designated as one for patients under intubation. Acute respiratory distress syndrome (ARDS) was defined by $\mathrm{PaO}_{2} / \mathrm{FiO}_{2}<200$ regardless of positive endexpiration pressure (PEEP) level, on the basis of a previous definition of ARDS [14]. PERF was defined in the following events: (1) when reintubation was performed within $48 \mathrm{~h}$ after extubation, (2) when prophylactic NPPV was required for more than $48 \mathrm{~h}$, and (3) when a rescue NPPV was performed under conventional oxygen therapy within $48 \mathrm{~h}$ after extubation.

\section{Statistical analysis}

All patients were analyzed on an intention-to-treat basis. For continuous variables, mean \pm standard deviation (SD) or median and $25 \%$ and $75 \%$ percentile values were calculated. Comparison between the two groups was performed using the Mann-Whitney $U$ test. All statistical analyses were performed with EZR (Saitama Medical Center, Jichi Medical University), which is a graphical user interface for $\mathrm{R}$ (The $\mathrm{R}$ Foundation for Statistical Computing, version 2.13.0) [15]. EZR is a modified version of the $\mathrm{R}$ commander (version 1.6-3) that includes statistical functions that are frequently used in biostatistics.

\section{Results}

Of 464 consecutive patients who received MV for more than $48 \mathrm{~h}, 216$ were excluded for the following reasons: death during MV $(n=98)$, tracheotomy $(n=87)$, selfextubation $(n=8)$, and transfer from the center to the general ward or another hospital under MV $(n=23)$ (Fig. 3). The remaining 248 patients were deemed eligible for this study. Table 1 presents the baseline characteristics of the study population. The median patient age was 65 years (mean age, $65 \pm 17$ years). Reasons for MV included ARDS $(n=159 ; 64.1 \%)$, congestive heart failure (CHF) $(n=57 ; 23.0 \%)$, and post-cardiac arrest syndrome $(n=30 ; 12.1 \%)$. All 248 patients were extubated after a 30-min SBT and application of the extubation protocol. Of the 248 patients, 213 patients received conventional oxygen therapy, and the remaining 35 patients received prophylactic NPPV.

Overall, 224 patients were successfully extubated, while 24 patients had PERF. There were 23 cases of 
First risk assessment checklist: tolerance for spontaneous breathing trial (SBT) Spontaneous breathing for 30 minutes through ventilator with "flow trigger" mode rate set to 0 , PSV set to 0 , PEEP $5 \mathrm{~cm} \mathrm{H}_{2} \mathrm{O}$ or a T-tube.

The following seven items are checked to judge the successful SBT

(1) Respiratory rate $(\mathrm{RR})>35 / \mathrm{min}$ for 5 minutes or more

(2) Rapid shallow breathing index $(\mathrm{RSBI})>100 \mathrm{cycles} / \mathrm{min} / \mathrm{L}$

(3) $\mathrm{SaO}_{2}<90 \%$ for 5 minutes or more

(4) Heart rate $(\mathrm{HR})>120 / \mathrm{min}$, or sustained increase $20 \%$ greater than baseline

(5) Systolic blood pressure $<90 \mathrm{~mm} \mathrm{Hg}$ or $>180 \mathrm{~mm} \mathrm{Hg}$ for 5 minutes or more

(6) Emergence of a chest pain or a new electrocardiogram change

(7) Dyspnea, increased anxiety, and diaphoresis

Next, judge the patients' eligibility for extubation if they do not meet at least one of these seven criteria. If they meet at least one of these seven criteria, they are rested on mechanical ventilation until the next morning and rechecked the next day

Second risk assessment checklist: eligibility for extubation

The following seven items are checked to judge the eligibility of patients for extubation.

(1) No severe disturbance in level of consciousness (e.g., ability to protect the airway)

(2) Presence of cough reflex

(3) Presence of gag reflex

(4) Stable cardiovascular system (e.g., HR $<120$ beats/min; dopamine level $<5$ $\mu \mathrm{g} / \mathrm{kg} / \mathrm{min}$; no ischemic changes on electrocardiogram; and no severe cardiac arrhythmia)

(5) $\mathrm{RR}<35$ breaths/min

(6) $\mathrm{RSBI}<100$ breaths $/ \mathrm{min} / \mathrm{L}$

(7) Presence of cuff leak

Patients are extubated if they satisfy all of the above criteria. If they do not, mechanical ventilation is continued, and items in this checklist are rechecked the next day.

Third risk assessment checklist: evaluation for the use of prophylactic NPPV The following three items are checked for the use of prophylactic NPPV.

(1) Age $>65$ years

(2) Cardiac failure as the reason for intubation

(3) Increased severity of respiratory failure (e.g., APACHE II score at extubation > 12) If patients have at least one of three criteria in the risk assessment checklist, the use of prophylactic NPPV is considered. The final decision on prophylactic use of NPPV is left to the discretion of the attending physicians.

Fourth risk assessment checklist: evaluation after extubation

The following six items are checked to judge whether conventional oxygen therapy is sufficient within 48 hours after extubation and to judge the eligibility of patients for rescue NPPV or reintubation.

(1) RR $>35$ breaths $/$ min for 5 minutes or more

(2) $\mathrm{SpO}_{2}<90 \%$ for $5 \mathrm{~min}$ or more

(3) HR $>120$ beats/min or sustained increase of 20 beats/min over the baseline level for $5 \mathrm{~min}$ or more

(4) Systolic blood pressure $<90 \mathrm{mmHg}$ or sustained decrease of $30 \mathrm{mmHg}$ over the baseline level for 5 minutes or more

(5) Chest pain or electrocardiographic abnormalities (emergence of ischemic changes or arrhythmia)

(6) Dyspnea, increased anxiety, and diaphoresis

Patients who meet at least one of these six criteria are adjudged as requiring ventilatory assistance. Eligibility and contraindications for rescue use of NPPV are evaluated. Rescue NPPV is initiated if indicates; if not, tracheal intubation is performed

Attending physicians check this checklist $60 \mathrm{~min}$ after extubation, every morning and evening. Furthermore, ICU nurses check the vital signs once every hour. If the ICU nurse notices at least one abnormality out of six criteria, they told the attending physicians about the abnormality. Then, attending physician rechecked the checklist in each case.
Fig. 2 Details of a comprehensive protocol for ventilator weaning and extubation. SBT, spontaneous breathing trial; PSV, pressure support ventilation; PEEP, positive end-expiratory pressure; RR, respiratory rate; $\mathrm{RSBl}$, rapid shallow breathing index; $\mathrm{SaO}_{2}$, oxygen saturation; HR, heart rate; PERF, post-extubation respiratory failure; APACHE II, Acute Physiology and Chronic Health Evaluation II; NPPV, non-invasive positive pressure ventilation; $\mathrm{SpO}_{2}$, arterial oxygen saturation

PERF among the conventional oxygen therapy patients and one of 35 patients who underwent prophylactic NPPV. Of the 24 PERF patients, 13 eventually required reintubation. Of the 23 PERF patients receiving conventional oxygen therapy, 16 received rescue NPPV while 11 patients avoided reintubation. Protocol violation of the tolerance of SBT and eligibility for extubation risk assessments was observed in 20 (8\%) patients. Nevertheless, these patients were included in the analyses on an intention-to-treat basis. There was no instance of violation of the evaluation after extubation risk assessment.

The overall PERF and reintubation rates were 9.7\% $(24 / 248)$ and $5.2 \%$ (13/248), respectively. The 28-day, 60 -day, and hospital mortality rates were $1.2 \%, 4.4 \%$, and $6.9 \%$, respectively (Table 2 ).

\section{Comparison of patients with PERF $(n=24)$ and non-PERF $(n=224)$}

There was no significant difference in age and sex between the PERF and non-PERF groups (Table 1). There were no significant differences in vital signs and $A B G$ values just before extubation between the two groups. Regarding outcomes, hospital mortality tended to be higher $(16.7 \%$ vs $6.3 \%, p=0.057)$ and the length of CCC stay tended to be longer in PERF patients than in nonPERF patients (Table 2). But there was no difference in 28-day, 60-day mortality, and length of hospital stay between the groups. The reintubation rate was $54.1 \%$ in patients with PERF. Reintubated patients had a longer CCC stay than did patients without reintubation after PERF. But there was no significant difference in the length of hospital stay and hospital mortality between patients with and without reintubation. Ten patients with PERF underwent a tracheotomy after reintubation. An additional table file shows this in more detail (see Additional file 1).

\section{Subgroup analysis: characteristics and outcomes of prophylactic NPPV}

Among 248 patients, 35 received prophylactic NPPV. The most common reason for undergoing prophylactic NPPV, at 54\% (19/35), was "cardiac failure as the reason for intubation". Twenty-three patients fulfilled "age $>65$ years" and 21 patients fulfilled "APACHE II score at extubation >12." Compared to conventional oxygen 

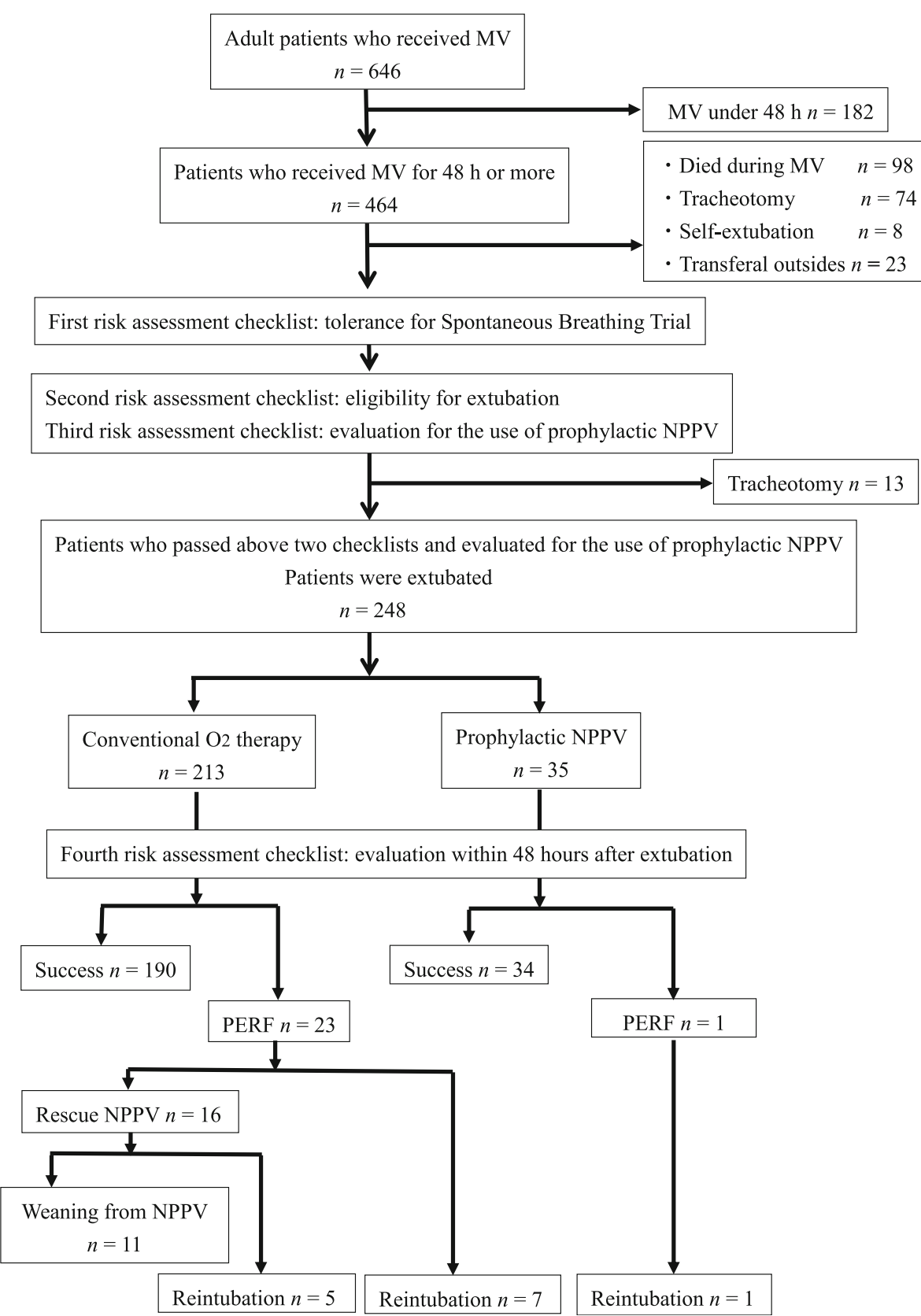

Fig. 3 Flow chart of the study patients. MV, mechanical ventilation; PERF, post-extubation respiratory failure; NPPV, non-invasive positive pressure ventilation

therapy, prophylactic NPPV was more frequently applied to patients with CHF $(p<0.001)$ and less frequently to patients with ARDS $(p=0.001)$. An additional table file shows this in more detail (see Additional file 2). Compared to conventional oxygen therapy, prophylactic NPPV exhibited significantly higher $\mathrm{SOFA}_{T}$ scores, RSBI, respiratory rate, $\mathrm{PaCO}_{2}(p=0.009,0.003,0.02$, and 0.02 , respectively), and significantly lower heart rate and $\mathrm{PaO}_{2} / \mathrm{FiO}_{2}$ ratio ( $p=0.02$ and $p<0.001$, respectively) just before extubation (Additional file 2). Outcomes did not differ significantly between prophylactic NPPV and conventional oxygen therapy. An additional table file shows this in more detail (see Additional file 3).

\section{Discussion}

This study showed that PERF and reintubation occurred infrequently (9.7\% and 5.2\%, respectively) and hospital mortality was low (6.9\%) by the use of a comprehensive protocol for ventilator weaning and extubation. 
Table 1 Patients' characteristics

\begin{tabular}{|c|c|c|c|c|}
\hline & $\begin{array}{l}\text { All patients } \\
(n=248)\end{array}$ & $\begin{array}{l}\text { PERF } \\
(n=24)\end{array}$ & $\begin{array}{l}\text { Non-PERF } \\
(n=224)\end{array}$ & $\begin{array}{l}p \\
\text { values }\end{array}$ \\
\hline Age (years) & $65 \pm 17$ & $64 \pm 18$ & $65 \pm 17$ & 0.8 \\
\hline Women, $n(\%)$ & $77(31)$ & $7(29)$ & $70(31)$ & 1.0 \\
\hline APACHE II score just before extubation & $13(10-16)$ & $12.5(11-16)$ & $13(10-16)$ & 0.8 \\
\hline SOFA $_{T}$ score just before extubation & $5(4-6)$ & $5(4-6.3)$ & $5(4-6)$ & 0.5 \\
\hline RSBI (breaths/min/L) & $44 \pm 21$ & $45 \pm 18$ & $44 \pm 21$ & 0.9 \\
\hline Duration of mechanical ventilation (days) & $7(5-11)$ & $7.5(5-13.3)$ & $7(5-11)$ & 0.6 \\
\hline Reason for mechanical ventilation, $n(\%)$ & & & & 0.2 \\
\hline ARDS & $159(64.1)$ & $14(58)$ & $145(65)$ & \\
\hline Congestive heart failure & $57(23.0)$ & $5(21)$ & $52(23)$ & \\
\hline Post-cardiac arrest syndrome & $30(12.1)$ & $4(16)$ & $26(12)$ & \\
\hline COPD exacerbation & $2(0.8)$ & $1(4)$ & $1(0.4)$ & \\
\hline Comorbid diseases, $n$ (\%) & & & & 0.4 \\
\hline COPD & $17(7)$ & $5(21)$ & $12(5)$ & \\
\hline Coronary artery disease & $35(14)$ & $5(21)$ & $30(13)$ & \\
\hline Chronic heart failure & $25(10)$ & $4(17)$ & $21(9)$ & \\
\hline Chronic renal failure & $14(6)$ & $1(4)$ & $13(6)$ & \\
\hline Diabetes mellitus & $44(18)$ & $8(33)$ & $36(16)$ & \\
\hline Hypertension & $85(34)$ & $9(38)$ & $76(34)$ & \\
\hline \multicolumn{5}{|l|}{ Vital signs just before extubation } \\
\hline Heart rate (beats/min) & $88 \pm 19$ & $88 \pm 19$ & $88 \pm 18$ & 0.9 \\
\hline MAP (mmHg) & $90 \pm 15$ & $89 \pm 16$ & $90 \pm 15$ & 0.6 \\
\hline RR (breaths/min) & $20 \pm 7$ & $20 \pm 6$ & $20 \pm 7$ & 0.9 \\
\hline \multicolumn{5}{|l|}{ ABG values just before extubation } \\
\hline $\mathrm{pH}$ & $7.45 \pm 0.04$ & $7.45 \pm 0.04$ & $7.45 \pm 0.04$ & 0.5 \\
\hline $\mathrm{PaCO}_{2}(\mathrm{mmHg})$ & $38 \pm 6$ & $39 \pm 5$ & $38 \pm 6$ & 0.5 \\
\hline $\mathrm{PaO}_{2} / \mathrm{FiO}_{2}$ & $301 \pm 83$ & $282 \pm 88$ & $303 \pm 83$ & 0.3 \\
\hline
\end{tabular}

Data are presented as mean \pm standard deviation, median and interquartile range, or number (percentage). PERF post-extubation respiratory failure, APACHE II

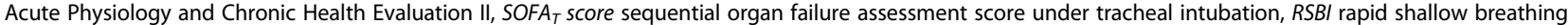
index, $A R D S$ acute respiratory distress syndrome, $C O P D$ chronic obstructive pulmonary disease, $M A P$ mean arterial pressure, $R R$ respiratory rate, $A B G$ arterial blood gas, $\mathrm{PaCO} 2$ partial pressure of carbon dioxide, $\mathrm{PaO}_{2}$ partial pressure of arterial oxygen, $\mathrm{FiO}_{2}$ fraction of inspired oxygen

Table 2 Outcome variables

\begin{tabular}{lllll}
\hline & $\begin{array}{l}\text { All patients } \\
(n=248)\end{array}$ & $\begin{array}{l}\text { PERF } \\
(n=24)\end{array}$ & $\begin{array}{l}\text { Non-PERF } \\
(n=224)\end{array}$ & $p$ values \\
\hline Reintubation, $n(\%)$ & $13(5.2)$ & $13(54.1)$ & - & - \\
CCC stay (days) & $20(12-33)$ & $25(16.8-47)$ & $19.5(12-32)$ & 0.058 \\
Hospital stay (days) & $33(21-52)$ & $44(25.8-57.8)$ & $33(20-51.3)$ & 0.16 \\
28-d mortality & $3(1.2)$ & $1(4.1)$ & $2(0.9)$ & 0.3 \\
60-d mortality & $11(4.4)$ & $1(4.1)$ & $10(4.5)$ & 1.0 \\
Hospital mortality & $17(6.9)$ & $4(16.7)$ & $13(6.3)$ & 0.057
\end{tabular}

Data are presented as median and interquartile range or number (percentage). PERF post-extubation respiratory failure, $C C C$ critical care center, $28-d$ mortality 28-day mortality after admission, 60- $d$ mortality 60-day mortality after admission
Studies have shown that PERF occurs in approximately $15 \%$ of cases and is associated with a high mortality rate of $25-50 \%[10,16]$. Reintubation has a reported association with increased mortality $[10,11,17,18]$ and the extubation failure rate is dependent on the type of patient [19]. PERF occurs in 5-8\% of critically ill surgical patients (trauma, cardiothoracic surgery, and general surgery), whereas $12-29 \%$ of pediatric, medical, multidisciplinary, and neurologic ICU patients $[1,4,10,16$, $17,19,20]$. The PERF rate in our CCC which was categorized as multidisciplinary ICU (Table 1) was less than those of previous studies. Hernández et al. [21] reported that the PERF rate and reintubation rate was $14.4 \%$ and $12.2 \%$, respectively, in a control group with a low APACHE II score of 7 at the time of extubation in a study investigating the effect of nasal high flow therapy. Ferrer 
et al. [11] reported a PERF rate of $33 \%$ in a control group with an APACHE II score at extubation of $13 \pm 3$ in a study investigating the effect of prophylactic NPPV. The PERF and reintubation rates in our study were lower than previous reports [21, 22] even though the APACHE II score just before extubation was 13. In the same study by Ferrer et al. [11], hospital mortality in patients receiving conventional oxygen therapy was $23 \%$. In our study, hospital mortality was lower than that in the aforementioned report even with nearly the same degrees of severity at extubation.

\section{Impact of the comprehensive protocol for ventilator weaning and extubation on reintubation rate and hospital mortality}

Reintubation is associated with a fivefold increase in death [10]. Low hospital mortality in our study seems to mainly result from low reintubation rates. Among patients with PERF, reintubated patients had equivalent outcomes compared with patients without reintubation. As a result, hospital mortality was reduced in our study, and the lower rate of reintubation and hospital mortality in our study are thought to be due to the comprehensive protocol for ventilator weaning and extubation. Each item in both weaning and extubation processes has already been reportedly used in previous studies. However, we believe that the comprehensive protocol per se, including all the processes of ventilator weaning and extubation, was effective in improving the outcomes by their synergistic effects. A systematic approach to ventilator weaning and extubation has been reported [3, 23], but this is the first report to investigate the effectiveness of a comprehensive protocol for ventilator weaning and extubation including prophylactic NPPV and evaluation after extubation.

\section{Implication of checklists on the comprehensive protocol for ventilator weaning and extubation \\ The evaluation of extubation to prevent PERF}

The extubation process is a critical component of respiratory care in patients who receive MV under tracheal intubation. However, the extubation process has not received the same attention as the process of ventilator weaning. Physicians do not always have similar judgment skills regarding extubation. This might be one of the reasons for the wide variation of reintubation rates among different institutions (range, 5-25\%) [1-3, 10, 11, 17]. Therefore, standardization of the extubation process as well as ventilator weaning is expected to minimize variability in judgment among physicians and the risk of PERF. To this end, we developed a comprehensive protocol for guiding the decision-making process regarding ventilator weaning and extubation.
Our extubation checklist included airway protection and patency factors. Cough reflex [7] and gag reflex [24] as factors of airway protection have been reported. The level of consciousness [4] and the cuff leak test [8] as factors of airway patency have been reported. Each factor has been reported to be an important predictor of extubation failure. Moreover, similar to the other reports $[9,25]$, the synergistic effect of checking predictors of PERF may play a role in our results.

\section{The effect of prophylactic NPPV in high risk of PERF}

NPPV has not been effective when used routinely after extubation in unselected patients [26]. However, Nava et al. reported that early application of NPPV was effective in preventing PERF in an at-risk population [27]. Ferrer et al. also reported that early use of NPPV averted PERF and decreased mortality among patients at increased risk of PERF [11]. Therefore, extubation processes including prophylactic NPPV may be effective for reducing PERF and reintubation. In this study, reintubation, PERF, and mortality rates of patients who had high risk of PERF and received prophylactic NPPV were not different from those of patients who received conventional oxygen therapy. These findings are consistent with those of previous reports [11,27].

"Cardiac failure as the reason for intubation" was the most common reason for undergoing prophylactic NPPV. Some studies reported that NPPV benefited patients with cardiac failure $[28,29]$. The favorable results of our study might have been partially because patients with congestive heart failure were selected as being at high risk of PERF by the protocol and underwent prophylactic NPPV.

Meanwhile, risk factors for PERF have been recently reported $[7,24,25,27,30]$. Hernández et al. reported that risk factors included older age, APACHE II greater than 12 , body mass index greater than $30 \mathrm{~kg} / \mathrm{m}^{2}$, inadequate secretions management, difficult or prolonged weaning, more than one comorbidity, heart failure as an indication for mechanical ventilation, moderate to severe chronic obstructive pulmonary disease, airway patency problems, and prolonged mechanical ventilation [30]. In our study, we investigated only three risk factors of PERF. If our third checklist had had items that could be used to detect patients who required prophylactic NPPV, some of the 23 patients with PERF in conventional $\mathrm{O}_{2}$ therapy group might have received prophylactic NPPV and avoided PERF.

\section{The evaluation after extubation to prevent reintubation and to reduce mortality}

It has been reported that the mortality rate increased in proportion to the interval between extubation and reintubation [31]. Thus, the timing of reintubation also 
seems to influence hospital mortality. In our study, patients were evaluated by the use of the fourth risk assessment checklist once every hour after extubation. The status of patients was rapidly assessed without delay in this protocol. Outcomes of patients with PERF were not significantly different from those of those without PERF. It also might be said that the fourth checklist is the one effect that reduced the risk considerably. It is quite possible that the evaluation after extubation risk assessment contributed to the reduction of overall mortality. Or it is possible to say that the first three checklists might have accelerated the detection of those patients who were in need of reintubation which were identified by the fourth checklist.

\section{Limitations}

There are limitations to the present study. First, this study used an observational and non-interventional design, which entails the risk of bias. Second, this study was conducted at a single center, and the results might not be generalizable to other institutions. Third, in this study, unfortunately, blinding of the investigator could not have been done. Moreover, there is difficulty in achieving blinding of the attending physicians in this type of clinical study; this might have led to potential performance bias. Fourth, generally, a before-and-after design is used to evaluate the effectiveness of a protocol in a single center study. However, we have administered our advanced emergency and critical care center in 2007 and have simultaneously used this protocol. Thus, we could not compare before-and-after designs. Fifth, the use of high flow nasal cannula oxygenation with critically ill adults has been increasing dramatically [32] and reported to be effective in patients after planned extubation $[21,30]$. Unfortunately, its use was not a standard treatment approach in adults still, when we developed this protocol. High flow nasal cannula oxygenation may be increasingly used for patients with high risk of PERF $[32,33]$. A multicenter clinical trial is needed to demonstrate the benefits of a comprehensive protocol for ventilator weaning and extubation.

\section{Conclusion}

A comprehensive protocol for ventilator weaning and extubation in critically ill patients may prevent PERF and reintubation and reduce mortality.

\section{Supplementary information}

Supplementary information accompanies this paper at https://doi.org/10. 1186/s40560-019-0402-4

Additional file 1. Outcomes in patients with and without reintubation after PERF.
Additional file 2. Comparison of patient characteristics with prophylactic NPPV and conventional oxygen (O2) therapy.

Additional file 3. Comparison of outcome variables with prophylactic NPPV and conventional oxygen (O2) therapy.

\section{Abbreviations}

ABG: Arterial blood gas; APACHE II: Acute Physiology and Chronic Health Evaluation II; ARDS: Acute respiratory distress syndrome; CCC: Critical care center; COPD: Chronic obstructive pulmonary disease; $\mathrm{FiO}_{2}$ : Fraction of inspired oxygen; GCS T: Glasgow Coma Scale under tracheal intubation; HR: Heart rate; MAP: Mean arterial pressure; MV: Mechanical ventilation; NPPV: Non-invasive positive pressure ventilation; $\mathrm{PaCO}$ : Partial pressure of carbon dioxide; $\mathrm{PaO}_{2}$ : Partial pressure of arterial oxygen; PEEP: Positive endexpiratory pressure; PERF: Post-extubation respiratory failure; RR: Respiratory rate; RSBI: Rapid shallow breathing index; SBT: Spontaneous breathing trial;

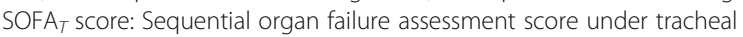
intubation; $\mathrm{SpO}_{2}$ : Arterial oxygen saturation

\section{Acknowledgements}

Not applicable.

\section{Authors' contributions}

NK designed the study, analyzed the data, and drafted the manuscript. OK was involved in the conception and design of the study and the critical revision of the manuscript. IH was involved in the critical revision of the manuscript. MK, TH, KH, OM, TK, YK, and TS contributed to the protocol development for the study and collection and interpretation of the patient data. All authors have read and approved the final manuscript.

\section{Funding}

The authors declare that they received no funding for this study.

\section{Availability of data and materials}

The dataset supporting the conclusions of this article is included within the article.

Ethics approval and consent to participate

This study was approved by the ethics review board of Shinshu University School of Medicine (Approval Number: 2652), and consent for research participation was deemed to be waived.

\section{Consent for publication}

Not applicable.

\section{Competing interests}

The authors declare that they have no competing interests.

Received: 27 May 2019 Accepted: 13 September 2019

Published online: 06 November 2019

\section{References}

1. Khamiees M, Raju P, DeGirolamo A, Amoateng-Adjepong Y, Manthous CA. Predictors of extubation outcome in patients who have successfully completed a spontaneous breathing trial. Chest. 2001;120:1262-70.

2. Krishnan JA, Moore D, Robeson C, Rand CS, Fessler HE. A prospective, controlled trial of a protocol-based strategy to discontinue mechanical ventilation. Am J Respir Crit Care Med. 2004:169:673-8.

3. Navalesi P, Frigerio P, Moretti MP, Sommariva M, Vesconi S, Baiardi P, Levati A. Rate of reintubation in mechanically ventilated neurosurgical and neurologic patients: evaluation of a systematic approach to weaning and extubation. Crit Care Med. 2008:36:2986-92.

4. Namen AM, Ely EW, Tatter SB, Case LD, Lucia MA, Smith A, et al. Predictors of successful extubation in neurosurgical patients. Am J Respir Crit Care Med. 2001:163:658-64.

5. Tobin MJ, Laghi F. Extubation. In: Tobin MJ, editor. Principles and practice of mechanical ventilation. 2nd ed. New York: McGraw-Hill; 2004. p. 1221-37.

6. Maclntyre NR, Cook DJ, Ely EW Jr, Epstein SK, Fink JB, Heffner JE, et al. Evidence-based guidelines for weaning and discontinuing ventilatory support: a collective task force facilitated by the American College of Chest 
Physicians; the American Association for Respiratory Care; and the American College of Critical Care Medicine. Chest. 2001;120:375S-95S.

7. Duan J, Zhou L, Xiao M, Liu J, Yang X. Semiquantitative cough strength score for predicting reintubation after planned extubation. Am J Crit Care. 2015;24:e86-90.

8. De Bast $Y$, De Backer D, Moraine JJ, Lemaire M, Vandenborght C, Vincent JL. The cuff leak test to predict failure of tracheal extubation for laryngeal edema. Intensive Care Med. 2002;28:1267-72.

9. Salam A, Tilluckdharry L, Amoateng-Adjepong Y, Manthous CA. Neurologic status, cough, secretions and extubation outcomes. Intensive Care Med. 2004:30:1334-9.

10. Frutos-Vivar F, Esteban A, Apezteguia C, González M, Arabi Y, Restrepo MI, et al. Outcome of reintubated patients after scheduled extubation. J Crit Care. 2011;26:502-9.

11. Ferrer M, Valencia M, Nicolas JM, Bernadich O, Badia JR, Torres A. Early noninvasive ventilation averts extubation failure in patients at risk: a randomized trial. Am J Respir Crit Care Med. 2006;173:164-70.

12. Kikuchi T, Toba S, Sekiguchi Y, Iwashita T, Imamura H, Kitamura M, et al. Protocol-based noninvasive positive pressure ventilation for acute respiratory failure. J Anesth. 2011;25:42-9.

13. Coplin WM, Pierson DJ, Cooley KD, Newell DW, Rubenfeld GD. Implications of extubation delay in brain-injured patients meeting standard weaning criteria. Am J Respir Crit Care Med. 2000;161:1530-6.

14. Bernard GR, Artigas A, Brigham KL, Carlet J, Falke K, Hudson L, et al. The American-European Consensus Conference on ARDS. Definitions, mechanisms, relevant outcomes, and clinical trial coordination. Am J Respir Crit Care Med. 1994;149:818-24.

15. Free Statistical Software: EZR (Easy R) on R Commander, http://www.jichi.ac. jp/saitama-sct/SaitamaHP.files/statmedEN.html, Accessed 1 Mar 2012.

16. Esteban A, Frutos-Vivar F, Ferguson ND, Arabi Y, Apezteguía C, Gonza'lez M, et al. Noninvasive positive-pressure ventilation for respiratory failure after extubation. N Engl J Med. 2004:350:2452-60

17. Seymour CW, Martinez A, Christie JD, Fuchs BD. The outcome of extubation failure in a community hospital intensive care unit: a cohort study. Crit Care. 2004;8:R322-7.

18. Epstein SK. Noninvasive ventilation to shorten the duration of mechanical ventilation. Respir Care. 2009;54:198-208.

19. Epstein SK. Decision to extubate. Intensive Care Med. 2002:28:535-46.

20. Epstein SK. Extubation. Respir Care. 2002;47:483-92.

21. Hernández G, Vaquero C, González P, Subira C, Frutos-Vivar F, Rialp G, et al. Effect of Postextubation high-flow nasal cannula vs conventional oxygen therapy on reintubation in low-risk patients: a randomized clinical trial. JAMA. 2016;315:1354-61.

22. Esteban A, Frutos-Vivar F, Muriel A, Ferguson ND, Peñuelas O, Abraira $V$, et al. Evolution of mortality over time in patients receiving mechanical ventilation. Am J Respir Crit Care Med. 2013;188:220-30.

23. Dries DJ, McGonigal MD, Malian MS, Bor BJ, Sullivan C. Protocol-driven ventilator weaning reduces use of mechanical ventilation, rate of early reintubation, and ventilator-associated pneumonia. J Trauma. 2004;56: 943-51.

24. Colonel P, Houzé MH, Vert H, Mateo J, Mégarbane B, Goldgran-Tolédano D, et al. Swallowing disorders as a predictor of unsuccessful extubation: a clinical evaluation. Am J Crit Care. 2008:17:504-10.

25. Godet T, Chabanne R, Marin J, Kauffmann S, Futier E, Pereira B, et al. Extubation failure in brain-injured patients: risk factors and development of a prediction score in a preliminary prospective cohort study. Anesthesiology. 2017;126:104-14.

26. Jiang JS, Kao SJ, Wang SN. Effect of early application of biphasic positive airway pressure on the outcome of extubation in ventilator weaning. Respirology. 1999;4:161-5.

27. Nava S, Gregoretti C, Fanfulla F, Squadrone E, Grassi M, Carlucci A, et al. Noninvasive ventilation to prevent respiratory failure after extubation in high-risk patients. Crit Care Med. 2005;33:2465-70.

28. Gray A, Goodacre S, Newby DE, Masson M, Sampson F, Nicholl J. Noninvasive ventilation in acute cardiogenic pulmonary edema. N Engl J Med. 2008;359:142-51.

29. Vital FM, Ladeira MT, Atallah AN. Non-invasive positive pressure ventilation (CPAP or bilevel NPPV) for cardiogenic pulmonary oedema. Cochrane Database Syst Rev. 2013;(5):CD005351.

30. Hernández G, Vaquero C, Colinas L, Cuena R, González P, Canabal A, Sanchez S, Rodriguez ML, Villasclaras A, Fernández R. Effect of postextubation high-flow nasal cannula vs noninvasive ventilation on reintubation and postextubation respiratory failure in high-risk patients: a randomized clinical trial. JAMA. 2016;316:1565-74.

31. Epstein SK, Ciubotaru RL. Independent effects of etiology of failure and time to reintubation on outcome for patients failing extubation. Am J Respir Crit Care Med. 1998;158:489-93.

32. Nishimura M. High-flow nasal cannula oxygen therapy in adults. J Intensive Care. 2015:3:15.

33. Zhu $Y$, Yin $H$, Zhang $R$, Ye $X$, Wei J. High-flow nasal cannula oxygen therapy versus conventional oxygen therapy in patients after planned extubation: a systematic review and meta-analysis. Crit Care. 2019;23:180.

\section{Publisher's Note}

Springer Nature remains neutral with regard to jurisdictional claims in published maps and institutional affiliations.
Ready to submit your research? Choose BMC and benefit from:

- fast, convenient online submission

- thorough peer review by experienced researchers in your field

- rapid publication on acceptance

- support for research data, including large and complex data types

- gold Open Access which fosters wider collaboration and increased citations

- maximum visibility for your research: over $100 \mathrm{M}$ website views per year

At $\mathrm{BMC}$, research is always in progress.

Learn more biomedcentral.com/submissions 